\title{
Komposit Epoksi Diperkuat Serat Corypha Utan: Karakterisasi Morpologi, Kekuatan Tarik Dan kekuatan Lentur
}

\author{
Nasmi Herlina Sari1)*, Agus Dwi Catur ${ }^{1)}$, Ahmad Safii ${ }^{1)}$ \\ 1) Teknik Mesin Fakultas Teknik Universitas Mataram, Nusa Tenggara Barat, Indonesia
}

Naskah diterima 27/12/2019; direvisi 05/04/2019; disetujui 24/04/2019

doi: https://doi.org/10.24843/JEM.2019.v12.i01.p05

\begin{abstract}
Abstrak
Serat Corypha utan lamarck, yang kaya selulosa, murah, berlimpah memiliki potensi untuk penguatan pada komposit termoset. Penelitian ini bertujuan untuk menyelidiki sifat-sifat dari komposit epoksi berpenguatan serat Corypha utan lamarck. Pembuatan komposit telah dilakukan dengan menggunakan teknik vacuum bagging. Efek penambahan fraksi volume serat Corypha Utan (CU) dengan variasi 20, 25 dan 30 \% (fraksi volume) terhadap morpologi, sifat kekuatan tarik dan lentur dari komposit telah diselidiki dan dianalisa. Hasil studi menunjukkan bahwa penambahan fraksi volume serat Corypha Utan secara siknifikan meningkatkan kekuatan tarik dan lentur dari komposit; dikarenakan penyebaran serat merata dalam resin, dan interface yang cukup kuat terbentuk antara serat dan epoksi. Komposit CU/epoksi dengan variasi fraksi volume serat 30\% (spesimen komposit CUh) memiliki nilai kekuatan dan modulus tarik sebesar tur paling tinggi sebesar 28.13 MPa dan 39.40 MPa, berturut-turut. Modulus lentur paling tinggi dimiliki oleh komposit dengan fraksi volume serat CU sebesar $30 \%$. Analisa foto SEM memperlihatkan ikatan interface antara serat-epoksi dan fiber breakage. Hasil ini menunjukkkan bahwa komposit $\mathrm{Cu} / \mathrm{epoksi}$ dapat menjadi alternatif sebagai papan komposit komersil.
\end{abstract}

Kata kunci: serat Corypha Utan I, komposit, epoksi, sifat mekanik dan scanning electronic microscopy (SEM).

\section{Abstract}

Corypha Utan fiber, which is rich cellulose, cheap and abundant has the potential for reinforcement in thermoset composites. This study aim is to investigate the properties of epoxy composites reinforced Corypha Utan fibers. The manufacture of composite has been done using vacuum bagging technique. The effect of increasing of the volume fraction of the Corypha utan fibers with variations of 20, 25 dan $30 \%$ (volume fraction) on morphology, the tensile and flexural strength of composites have been investigated and analyzed. The results show that the increase of the volume fraction of Corypha utan fibers significantly increased tensile and flexural of composites; it is due to the dispersion of the fibers in epoxy, and interface bond between fiber and epoxy formed strong enough. The CU/epoxy composite with the volume fraction of the fiber of $30 \%$ (Composite CUh specimens) has the highest tensile and flexural strength value of $28,13 \mathrm{MPa}$ and $39,400 \mathrm{MPa}$, respectively. The moduli's flexural gives higher value at $30 \%$ volume fraction. SEM images demonstrate that interfacial adhesions between fiber-epoxy, and fiber breakage. The result suggests that Corypha utan fibers/epoxy composites can be a good alternative as commercial composites boards, especially for interior applications.

Keywords: Corypha utan I. fibers, composites, epoxy, mechanical properties and scanning electronic microscopy.

\section{Pendahuluan}

Tuntutan akan komponen atau material yang ringan dan mampu struktural mengalami peningkatan yang signifikan. Salah satu material yang dapat memenuhi hal tersebut ialah material komposit yang diperkuat serat alam, seperti daun pandan, cornhusk, batang kelapa dan lidah mertua [1-4]. Murah, mudah diproses, renewable, berlimpah dan tidak membahayakan kesehatan manusia [5,6]; keunggulan ini telah menjadikan serat alam lainnya menarik untuk diselidiki sifatsifatnya.

Salah satu potensi serat alam yang pemanfaatannya masih perlu dikembangkan lagi adalah serat dari Corypha utan lamarck. Tanaman Corypha utan lamarck masuk dalam family Palmae, kelas Monocotyl dan sub divisi Angiospermae. Corypha Utan dapat tumbuh dengan ketinggian mencapai $15-20 \mathrm{~m}$, dan bagian puncaknya memiliki daun-daun berbentuk kipas bertangkai atau berpelepah panjang. Mereka tumbuh di daerah dataran rendah dan berbukit [7].

Beberapa peneliti telah memanfaatkan dan mempelajari sifat mekanik dari komposit serat dari Corypha utan lamarck. Ndoen et al. [8] mempelajari efek penambahan serat daun corypha utan lam terhadap kuat lentur dan tarik dari belah balok beton. Mereka menunjukkan bahwa penambahan serat daun Corypha utan sebesar $0.75 \%$ mempunyai kuat lentur dan tarik belah beton maksimum sebesar $5.96 \mathrm{MPa}$ dan 3.94 $\mathrm{MPa}$, berturut-turut. Sabuin et al. [9] telah menghibrid serat daun Corypha utan dengan serat gelas untuk melihat efek temperatur pengovenan terhadap sifat mekanik komposit. Mereka melaporkan bahwa kenaikan temperatur

\footnotetext{
*Korespondensi:

E-mail: n.herlinasari@unram.ac.id
} 
menurunkan sifat mekanik dari komposit hibrid. Kekuatan tarik tertinggi diperoleh pada komposit yang dipanaskan pada temperatur $100^{\circ} \mathrm{C}$ selama 1 jam memiliki kekuatan tarik sebesar $62.26 \mathrm{Mpa}$, dan terendah sebesar 28.80 Mpa dimiliki oleh komposit dengan pemanasan $200{ }^{\circ} \mathrm{C}$ selama 3 . Tegangan bending tertinggi diperoleh dari komposit pada temperatur $100{ }^{\circ} \mathrm{C}$ selama 1 jam sebesar 112.34 MPa dan terendah sebesar 57.71 $\mathrm{MPa}$ (pada temperatur $200{ }^{\circ} \mathrm{C}$ selama 2 jam). Kemudian, Dewi et al. [10] telah mempelajari sifat curing, mekanik, dan morfologi pada komposit CR/NR. Rasio CR:NR adalah 100:0, 90:10, 80:20, dan 70:30, berturut-turut. Serat gebang (Corypha utan) telah klorinasi dan alkalinisasi. Mereka melaporkan bahwa bertambahnya serat Corypha utan meningkatkan kekerasan dan ketahanan sobek komposit sebesar 2.95\% dan $140.41 \%$, berturut-turut. Namun, tegangan dan perpanjangan putus menurun sebesar $42 \%$ dan $9.59 \%$. Sedangkan, Abanat et al. [11] telah melaporkan efek fraksi volume serat pelepah Corypha utan lam terhadap sifat mekanik komposit epoksi. Mereka melaporkan bahwa kekuatan tarik dan impak tertinggi diperoleh pada komposit dengan fraksi volume serat $70 \%$ sebesar 5.3 $\mathrm{kgf} / \mathrm{mm}^{2}$ dan $0,215 \mathrm{~J} / \mathrm{mm}^{2}$ berturut-turut. Dari studistudi sebelumnya ini menunjukkan bahwa penyelidikan terhadap morpologi, kekuatan tarik dan lentur dari komposit serat pelepah Corypha utan I. masih perlu diselidiki lebih detil untuk mengembangkan potensi dari serat Corypha utan I. sebagai bahan penguat komposit.

Oleh sebab itu, paper ini bertujuan untuk memberikan pemahaman lebih detil terkait dengan karakteristik morpologi, sifat kekuatan tarik dan lentur dari komposit epoxi diperkuat serat pelepah Corypha utan lamarck, CU. Penambahan fraksi volume serat $\mathrm{CU}$ dalam komposit dilakukan untuk menyelidiki morpologi SEM, kekuatan lentur dan kekuatan tarik dari komposit. Hasil penelitian diharapkan memberikan informasi dan pemahaman terkait dengan komposit diperkuat serat CU dan dapat menjadi alternatif bahan komposit untuk aplikasi interior seperti; dudukan bantal mobil, meja, dan lain-lain.

\section{Metode Penelitian}

\subsection{Bahan}

Serat pelepah Corypha Utan lamarck (CU) diperoleh dari tumbuhan CU yang tumbuh liar di wilayah Lombok Barat, Indonesia. Diameter serat rata-rata yang digunakan $0.65 \pm 0.01 \mathrm{~mm}$. Panjang serat yang digunakan $300 \mathrm{~mm}$. Tanaman Corypha Utan dan seratnya diperlihatkan dalam gambar 1.

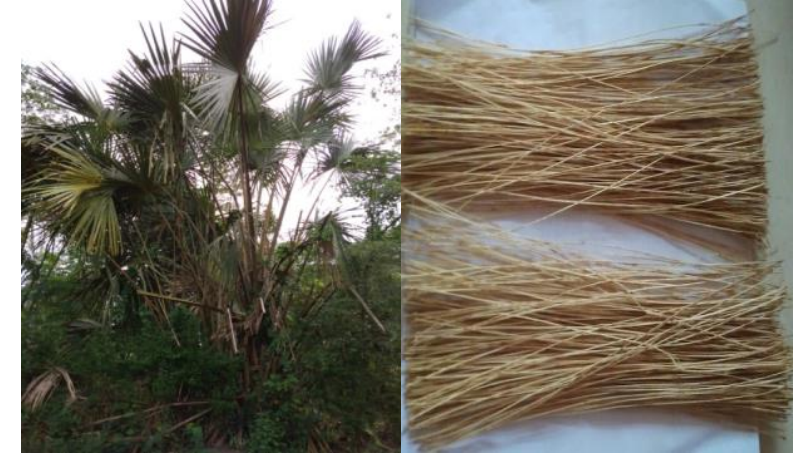

Gambar 1. Tanaman dan serat Corypha Utan.

Selanjutnya, resin epoksi telah digunakan sebagai pengikat (matrik) yang memiliki kekuatan dan modulus tarik sebesar $85 \mathrm{~N} / \mathrm{mm}^{2}$, dan 10,500 $\mathrm{N} / \mathrm{mm}^{2}$ berturut-turut. Kekuatan lentur dan modulus lentur sebesar $112 \mathrm{~N} / \mathrm{mm}^{2}$, dan 10,000 N/mm² berturut-turut.

\subsection{Pembuatan spesimen komposit}

Pembuatan komposit dilakukan menggunakan teknik vacuum bag moulding. Proses dimulai dengan mempersiapkan serat CU dan resin epoksi sesuai dengan rasio yang telah ditentukan (lihat Tabel 1), yaitu 20:80, 25:75 dan 30:70 (\% fraksi volume), sedangkan campuran antara epoksi dan hardener adalah 1:1. Selanjutnya, siapkan cetakan yang telah dilapisi dengan wax, kemudian tuang setengah campuran epoksi ke dalam cetakan dan serat CU diletakkan dibagian atasnya. Selanjutnya, sisa epoksi dituang kembali pada bagian atas serat dan dikuti dengan menutup cetakan.

Proses selanjutnya, bungkus sisi-sisi cetakan menggunakan busa; yang dimaksudkan untuk mencegah terjadinya sobekan pada plastik vacuum oleh penjepit klip dan sisi-sisi cetakan kaca yang tajam dan letakkan ke dalam vacuum bag (lihat gambar 2).

Tabel 1 Rasio komposisi fraksi volume serat Corypha Utan dan epoksi.

\begin{tabular}{cccc}
$\begin{array}{c}\text { Kode } \\
\text { spesimen }\end{array}$ & CUs & CUn & CUh \\
$\begin{array}{c}\text { Serat } \\
\text { Corypha Utan }\end{array}$ & 20 & 25 & 30 \\
\hline Epoksi & 97.5 & 90 & 85 \\
\hline
\end{tabular}

Kemudian, tutup rapat-rapat vacuum bag lalu sedot udara didalamnya dengan menggunakan motor vacuum sampai panah pada vacuum pressure gauge menunjukkan nilai $-60 \mathrm{cmHg}$ Akhirnya, komposit dikeluarkan dari dalam cetakan setelah dikeringkan selama 15 jam. 


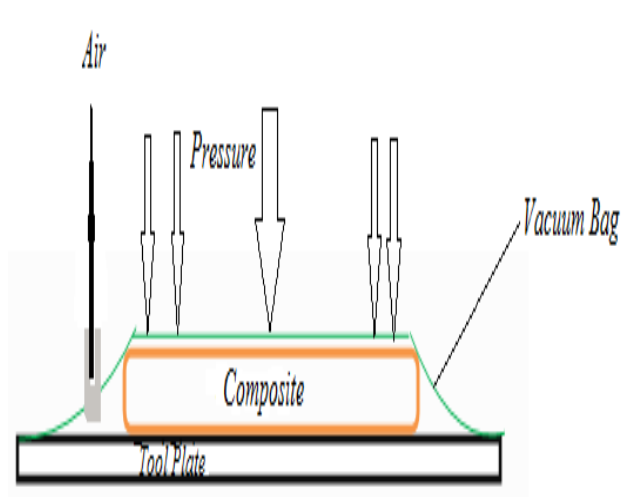

Gambar 2. Vacuum bag moulding

\subsection{Uji kekuatan tarik komposit}

Kekuatan dan regangan tarik dari komposit CU/epoksi ditentukan menurut standar internasional ASTMD-3039 [12]. Pengukuran nilai kekuatan tarik dan lentur telah dilakukan dengan menggunakan mesin uji Tensilon RTG-1310 dengan kecepatan $1.5 \mathrm{~mm} /$ menit. Dimensi spesimen uji tarik disajikan dalam gambar $3 a$.

2.4. Uji kekuatan tarik komposit

Uji kekuatan lentur dari komposit ditentukan dengan ASTM D790-92 [13]. Dimensi spesimen komposit untuk uji lentur ditunjukkan dalam gambar 3b. Setiap variasi parameter uji dilakukan pengulangan sebanyak tiga kali.

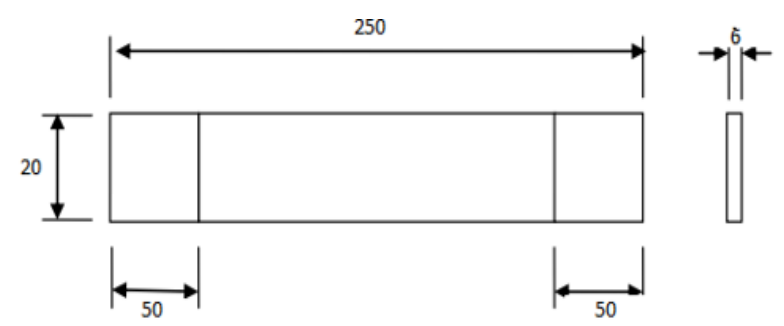

(a)

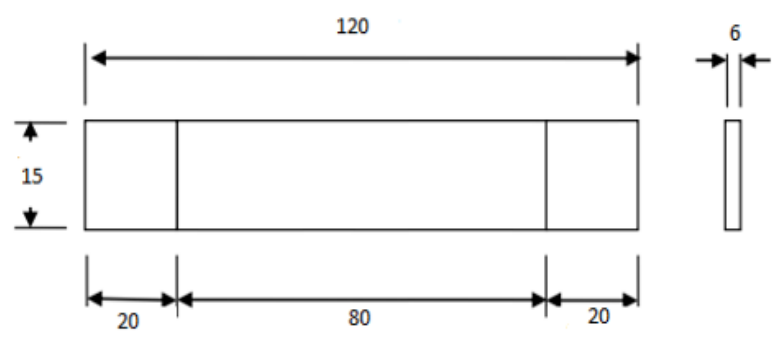

(b)

Gambar 3. Spesimen uji, a. uji tarik, b. lentur (dalam $\mathrm{mm}$ ).

\subsection{Scanning Electron Microscopy, SEM}

Morpologi patahan komposit CU/epoksi diamati dan dianalisa menggunakan SEM. Spesimen direkatkan pada holder menggunakan double sticky tape. Spesimen uji diletakkan dalam mesin couting untuk pelapisan gold-poladium selama 4 menit. Pembesaran gambar diatur untuk mendapatkan gambar yang jelas dan sesuai keinginan.

\section{Hasil dan Pembahasan}

\subsection{Analisa kekuatan tarik komposit}

Gambar 4 memperlihatkan kekuatan tarik ratarata komposit CU/epoksi cenderung meningkat dengan bertambahnya fraksi volume serat CU dalam komposit. Kekuatan tarik rata-rata spesimen komposit CUs, CUn dan CUh masing-masing sebesar 16.45 $\mathrm{MPa}$, 18.91 $\mathrm{MPa}$, dan $28.13 \mathrm{MPa}$, berturut-turut. Peningkatan kekuatan tarik komposit ini dikarenakan ikatan interface antara epoksi - serat CU terbentuk kuat dengan bertambahnya serat; dengan demikian, komposit mampu menahan transfer tegangan yang tinggi, akibatnya kekuatan tarik komposit menjadi tinggi. Hasil ini juga telah dikonfirmasi dengan analisa SEM dalam bahasan berikutnya. Lebih lanjut, kekasaran permukaan serat CU (lihat gambar 5) dengan adanya shallow groove telah menambah kuatnya ikatan antara serat dan epoksi; sehingga kekuatan tarik yang dihasilkan besar.

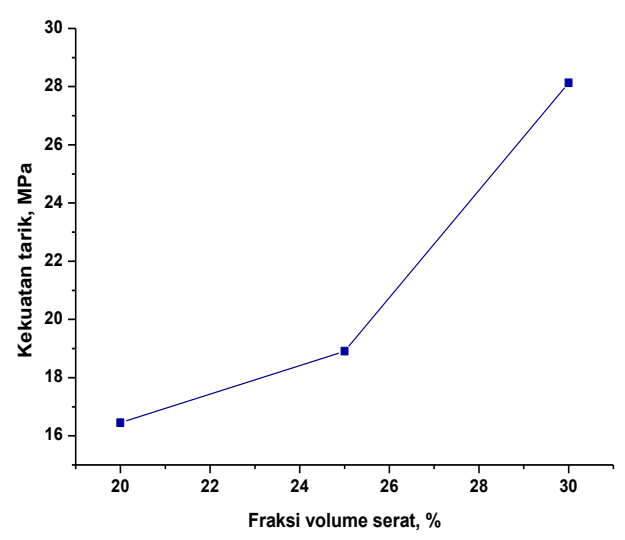

Gambar 4. Fraksi volume serat terhadap kekuatan tarik komposit CU/epoksi.

Dibandingkan dengan kekuatan tarik komposit jerami/epoksi dan komposit nilon/epoksi, kekuatan tarik rata-rata komposit CU/epoksi lebih tinggi dengan fraksi volume serat $30 \%$ yaitu $28.13 \mathrm{MPa}$. Kurniawan [14] melaporkan bahwa kekuatan tarik rata-rata tertinggi dimiliki oleh komposit jerami/epoksi yaitu $19.68 \mathrm{Mpa}$ (pada fraksi volume jerami 50\%). Demikian juga, Rusmiatno [15] menyatakan bahwa komposit nilon/epoksi pada fraksi volume nilon $60 \%$ memiliki kekuatan tarik sebesar 25.86 Mpa. Hasil ini menunjukkan bahwa komposit CU/epoksi dapat menjadi alternatif yang baik untuk papan komposit daripada kedua jenis komposit lainnya. 


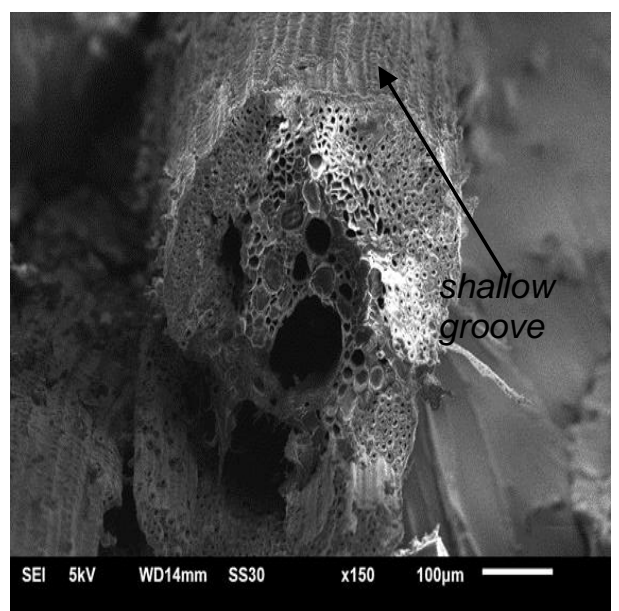

Gambar 5. Foto SEM dari serat Corypha Utan I.

Untuk spesimen komposit CUh, jumlah serat yang sedikit dalam komposit menghasilkan kemampuan serat untuk menahan transfer tegangan dari epoksi rendah; akibatnya kekuatan tarik yang dihasilkan rendah.

Gambar 6 menyajikan bahwa nilai regangan tarik rata-rata dari spesimen komposit CUs, CUn dan $\mathrm{CU}_{\mathrm{h}}$ masing-masing sebesar 0.059, 0.054, dan 0.062 , berturut-turut. Regangan meningkat akibat respon berlawanan dari komposit terhadap beban tarik yang diterima besar, sehingga komposit mengalami tegangan dan regangan sekaligus; dikarenakan efek pergeseran internal di tingkat atom pada bahan penyusun komposit; akibatnya komposit bertambah panjang, dengan demikian, regangan tarik yang dihasilkan bertambah besar, Sebaliknya, nilai regangan rendah (komposit CUn) karena respon berlawanan terhadap beban tarik yang diterima rendah.

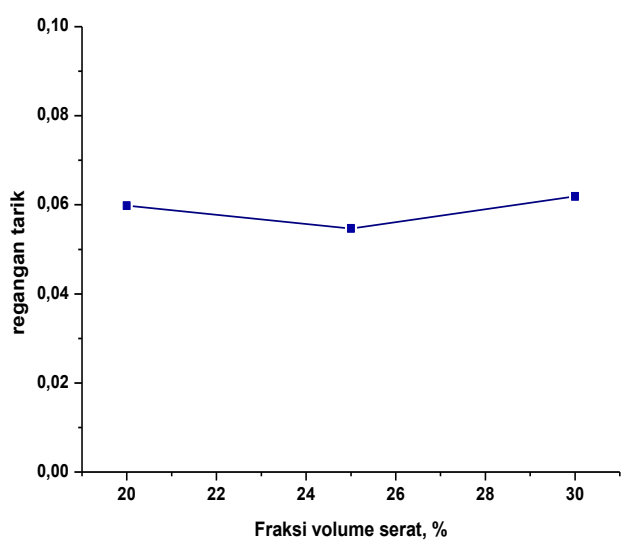

Gambar 6. Fraksi volume serat terhadap regangan tarik komposit CU/epoksi.

\subsection{Analisa kekuatan lentur komposit}

Gambar 7 menunjukkan bahwa kekuatan lentur dari komposit yang dihasilkan meningkat secara siknifikan. Kekuatan lentur paling tinggi ditemukan pada komposit CUh sebesar 39.40 MPa daripada dua komposit lainnya yang dipelajari. Peningkatan $5 \%$ fraksi volume serat telah secara siknifikan meningkatkan kekuatan lentur dari komposit. Penyebaran serat secara merata dalam resin dan kuatnya ikatan interface antara serat-epoksi, telah memberikan kemampuan komposit dalam menahan konsentrasi tegangan yang terjadi; sehingga kekuatan lenturnya menjadi tinggi.

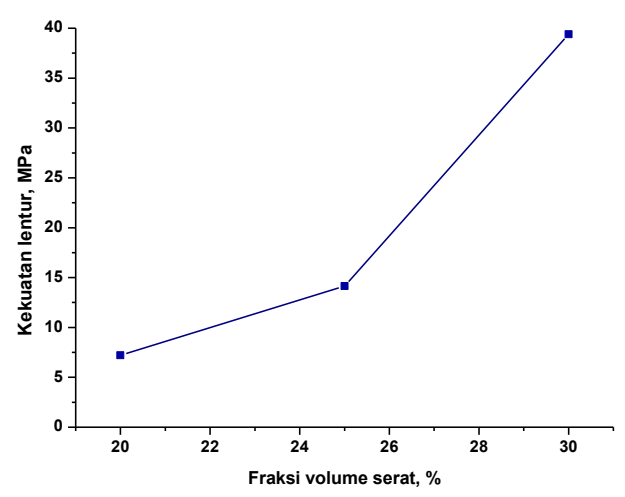

Gambar 7. Fraksi volume serat terhadap kekuatan lentur komposit CU/epoksi.

Alasan mengapa sifat kekuatan lentur dari komposit CUs rendah untuk fraksi volume 20\% dikarenakan interaksi serat-ke serat, penyebaran serat dan void. Arib et al. [16] menyatakan bahwa menurunnya sifat kekuatan lentur dari komposit polimer boleh jadi disebabkan interaksi yang rendah, penyebaran serat kurang merata dalam matrik dan void.

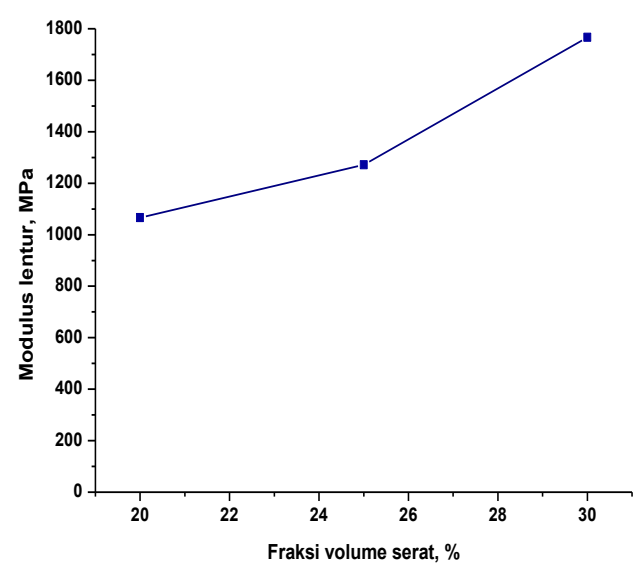

Gambar 8. Fraksi volume serat terhadap modulus elastisitas lentur komposit CU/epoksi

Gambar 8 menunjukkan modulus elastisitas dari komposit CU/epoksi. Komposit CUh memiliki nilai modulus elastisitas paling tinggi sebesar 1766.97 MPa daripada spesimen komposit CUn 
dan CUs masing-masing sebesar $1066.01 \mathrm{MPa}$, $1271.52 \mathrm{MPa}$, berturut-turut. Peningkatan modulus lentur ini disebabkan serat serat $\mathrm{CU}$ secara sempurna tersusun dalam matrik epoksi.

Untuk komposit CUs, modulus lenturnya paling rendah daripada komposit lainnya yang dipelajari; hal ini dikarenakan serat tidak tersusun sempurna dalam epoksi, masalah void dan serat tersebar tidak merata dalam matrik epoksi.

\subsection{Analisa SEM}

Morpologi patahan komposit CU/epoksi dianalisa dengan SEM. Gambar 9a, 9b, dan 9c. secara keseluruhan, semua spesimen komposit menunjukkan adanya mekanisme fiber pull out setelah patah. Foto SEM juga memperlihatkan adanya debonding yaitu lepasnya ikatan resin pada serat; hal ini yang menyebabkan kekuatan mekanik dari komposit cukup rendah. Terjadinya fiber pullout dan debonding pada komposit dikarenakan permukaan serat licin; adanya lapisan non-selulosa pada permukaan serat CU seperti lignin, hemiselulosa, dan wax [4]; sehingga kekuatan mekanik dari komposit cukup rendah (lihat gambar 9a).

Lebih lanjut, bertambahnya fraksi volume serat dalam resin epoksi, telah menghasilkan ikatan yang cukup kuat antara serat dan epoksi (lihat gambar 9b dan 9c); sehingga kekuatan mekanik komposit menjadi tinggi.

\section{Kesimpulan}

Investigasi morpologi, kekuatan tarik dan lentur dari komposit diperkuat serat CU telah dilakukan secara eksperimen. Bertambahnya fraksi volume serat $\mathrm{CU}$ dalam epoksi meningkatkan kekuatan tarik dan lentur dari komposit. Kekuatan tarik dan lentur terbaik diperoleh dari spesimen komposit Cuh sebesar 28.13 Mpa dan $39.40 \mathrm{Mpa}$; dikarenakan ikatan interface yang kuat dan penyebaran serat tersusun dalam epoksi. Foto patahan SEM menunjukkan adanya mekanisme fiber pull out dan debonding. Hasil penelitian ini menunjukkan bahwa komposit yang dihasilkan ini dapat menjadi alternatif yang baik untuk panel komposit epoksi/jerami dan epoksi nilon untuk aplikasi interior.
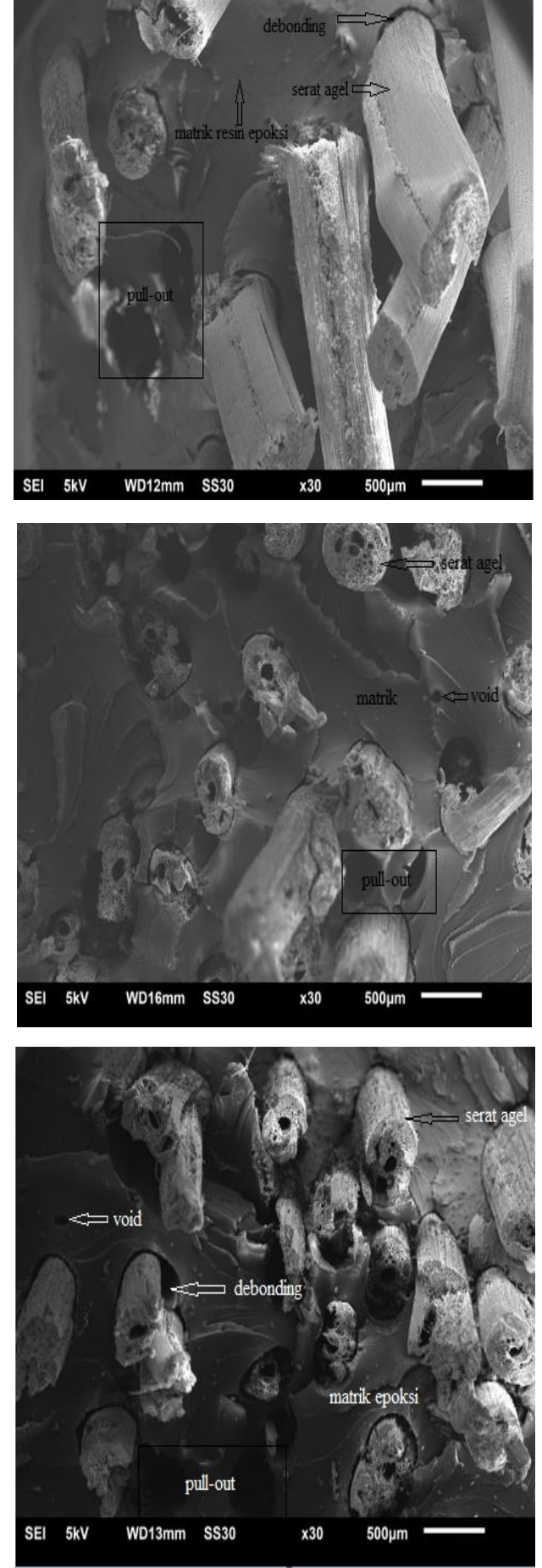

Gambar 9 Foto SEM dari komposit dengan fraksi volume serat CU berbeda, a. $20 \%$, b. $25 \%$ dan, c. $30 \%$. 


\section{Daftar Pustaka}

[1]. N.H. Sari, I.G.N.K. Yudhyadi, Karakteristik Kekuatan Bending Kayu Komposit Polyester Diperkuat Serat Pandan Wangi dengan Filler Serbuk Gergaji Kayu. Jurnal Energi Dan Manufaktur 6 (2): 157-164, 2013.

[2]. N.H. Sari, I.N.G. Wardana, Y.S. Irawan, E. Siswanto, Corn Husk Fiber - Polyester Composites as Sound Absorber: Nonacoustical and Acoustical Properties. Advances in Acoustics and Vibration. Volume 2017. https://doi.org/10.1155/2017/4319389.

[3]. J. Muslim, N.H. Sari, E.D. Sulistyowati, Analisis Sifat Kekuatan Tarik dan Kekuatan Bending Hybrid Serat Lidah Mertua Dan Karung Goni Dengan Filler Abu Sekam Padi $5 \%$ bermatrik epoxy, Dinamika teknik mesin 3 (1). 26-33, 2013. ISSN: 2088 - 088X.

[4]. N.H. Sari, 2018, Kekuatan mekanik komposit diperkuat serat selulosa. Dinamika Teknik Mesin, 8. 51-56.

[5]. N.H. Sari, I.N.G. Wardana, Y.S. Irawan, E. Siswanto, Characterization of the Chemical, Physical, and Mechanical Properties of $\mathrm{NaOH}$-treated Natural Cellulosic Fibers from Corn Husks, Journal of Natural Fibers, 15(4): 545-558.

doi: 10.1080/15440478.2017.1349707.

[6]. K. Oksmana, A.P. Mathew, R. Långström, B. Nyström, K. Joseph, The influence of fibre microstructure on fibre breakage and mechanical properties of natural fibre reinforced polypropylene, Composites Science and Technology 69, 1847-1853. 2009.

[7]. D.P. Sugiarto, Mengenal Flora TNRAW: Pemanfaatan Agel (Corypha utan), 2012. https://tnrawku.wordpress.com/2012/10/08/me ngenal-flora-tnraw-pemanfaatan-agelcorypha-utan/

[8]. V.G. Ndoen, D.A.T. Sina, W. Bunganaen, Pengaruh Penambahan Serat Daun Gewang (Corypha Utan Lam) terhadap Kuat Lentur dan Kuat Tarik Belah Beton, Jurnal Teknik Sipil Vol. IV, No. 1, 2015.

[9]. A. Sabuin, K. Boimau, D.G.H. Adoe, Pengaruh Temperatur Pengovenan terhadap Sifat Mekanik Komposit Hibrid Polyester Berpenguat Serat Glass dan Serat Daun Gewang, Lontar Jurnal Teknik Mesin Undana, Vol. 02, No. 01, 69-78, 2015.

[10]. I.R. Dewi, A. Yuniari, M. Sholeh, N.M. Setyadew, Penggunaan Serat Gebang Sebagai Bahan Pengisi Sekunder pada Komposit Karet Kloroprena /Karet Alam (CR/NR) Berpenguat Carbon Black, Prosiding Seminar Nasional Kulit, Karet, dan Plastik Ke5, Yogyakarta, 2016.

[11]. J.D.J. Abanat, A. Purnowidodo, Y.S. Irawan, Pengaruh Fraksi Volume Serat Pelepah
Gebang (Corypha Utan Lamarck) Terhadap Sifat Mekanik Pada Komposit Bermatrik Epoksi, Jurnal Rekayasa Mesin Vol. 3, No. 2: 352-361. 2012.

[12]. ASTM D3039 - 2008. Standard test method for tensile properties of plastics. ASTM Standards International.

[13]. ASTMD790 - 2010. Standard test methods for flexural properties of unreinforced and reinforced plastics and electrical insulating materials. ASTM Standards International.

[14]. W. Kurniawan, Karakterisasi material komposit jerami-epoksi yang dibuat dengan proses vacuum bag, Tugas Akhir, UPB, Bandung, 2011.

[15]. F. Rusmiatno, Pengaruh fraksi volume serat terhadap kekuatan tarik dan kekuatan bending komposit nilon/epoksi resin serat pendek, Tugas akhir, UNES, Semarang, 2007.

[16]. R.M.N. Arib, S.M. Sapuan, M.M.H.M. Ahmad, M.T. Paridah, H.M.D.K. Zaman, Mechanical properties of pineapple leaf fibre reinforced polypropylene composites, Materials and Design 27, 391-396, 2006. doi:10.1016/j.matdes.2004.11.009. 